\title{
NINTH CONFERENCE OF RED CROSS AND RED CRESCENT SOCIETIES OF THE BALKAN COUNTRIES
}

(Athens, 22-25 September 1991)

Organized by the Hellenic Red Cross, the Ninth Biennial Conference of the National Red Cross and Red Crescent Societies of the Balkan Countries took place in Athens from 22 to 25 September 1991. It was attended by leading members of the six National Societies of the Balkan countries (Albania, Bulgaria, Greece, Romania, Turkey and Yugoslavia) and, as guests. by delegations from the International Committee of the Red Cross (ICRC), the League of Red Cross and Red Crescent Societies, the Hungarian Red Cross. the Secretary General of the Conference of Arab Red Crescent and Red Cross Societies and a representative of the Henry Dunant Institute.

The ICRC's delegation was led by its President, Mr. Cornelio Sommaruga, accompanied by Dr. Rémi Russbach, Chief Medical Officer. Mr. Thierry Germond, Delegate General for Europe and North America, and Mr. Michel Martin, adviser on relations with the Movement. The League was represented by its President, Mr. Mario Villarroel Lander, Mr. Manuel Fiol, Head of Protocol, and Mr. Peter Titjes, Regional Delegate for Central and Eastern Europe.

Key features of the opening ceremony were messages from the Prime Minister and from the Greek Minister of Foreign Affairs, and addresses by the Presidents of the ICRC, the League and the Hellenic Red Cross. Mr. Sommaruga remarked in particular that recent changes within several of the National Societies present gave them an opportunity to adopt a new approach towards the Movement's Fundamental Principles, especially impartiality, neutrality and independence. He also stressed the importance for National Societies of having a democratic structure and remaining open to all: these, together with faithful adherence to the Principles, were guarantees for their development and the effectiveness of their work.

Discussions at the Conference concentrated on strengthening cooperation amongst the National Societies of the Balkan countries and on increased preparedness for emergency situations. In this connection, the Hellenic Red Cross put forward proposals for the development of joint medical, hygiene and social activities. A proposal to train joint medical teams to intervene 
during emergencies led Dr. Russbach to draw attention to the experience acquired by the ICRC Medical Division in this sphere and the need for appropriate coordination within the Movement.

Giving an account of their activities since the previous Conference and of the fresh difficulties they were currently facing, the representatives of the Albanian, Bulgarian, Romanian and Yugoslav Red Cross Societies expressed their gratitude for the Movement's support since they began reorganizing their Societics. In particular, the head of the Red Cross of Yugoslavia's delegation expressed his satisfaction at the close cooperation established with ICRC delegates in helping the victims of the current armed conflict. Having observed from experience that the legal regulations applicable to non-international conflicts were inadequate, he made a strong plea for States to grant a greater role to the Red Cross, and especially to the ICRC, in responding to these situations. For the present, it was important to make humanitarian law known, to create a customary basis that would pave the way for new laws more binding on Parties and, in any case, to make National Societies better prepared to handle such situations.

The participants also discussed a series of topics introduced by eminent members of the Hellenic Red Cross. In particular, these concerned the recruitment of motivated and active volunteer workers, assistance to refugees, cooperation between the tracing services of the Balkan Societies, the dissemination of international humanitarian law within the armed forces, the Strategic Work Plan of the League for the Nineties, and the general coordination of relief for civilians, victims of disasters or armed conflicts.

The representatives of the Hellenic Red Cross, the Hungarian Red Cross and the ICRC then gave details of the preparations and agenda for the 1991 International Conference of the Red Cross and Red Crescent in Budapest and on the invitations which had been issued.

A final declaration was adopted by consensus, as is standard practice, the gist of which is as follows:

- it expresses the participants' sympathy and appreciation for the efforts of the Red Cross of Yugoslavia and the outstanding work of its volunteers, and appeals to all parties involved to respect and ensure respect for international humanitarian law and to support the work of the ICRC in Yugoslavia;

- it reaffirms the participants' support for the Strategic Work Plan of the League for the Nineties;

- it thanks the Hellenic Red Cross for its proposals on cooperation and expresses the wish that the other Balkan Societies be given time to study them in greater depth, to discuss them again and to take the appropriate 
decisions at a subsequent meeting in Budapest in November 1991, during the 26th International Conference of the Red Cross and Red Crescent.

The participants lastly accepted the offer by the Bulgarian Red Cross to host the next Conference of the Balkan National Societies in Sofia in 1993 and expressed their gratitude to the Hellenic Red Cross for its excellent organization of the Ninth Conference and for the warm hospitality extended to all guests. 